Pacific Journal of Mathematic 


\title{
PROJECTIONS IN THE SPACES OF BOUNDED LINEAR OPERATORS
}

\author{
TSANG-HAI KUO
}

\begin{abstract}
For Banach spaces $X, Z$, let $B(X, Z)$ denote the space of bounded linear operators from $X$ into $Z$ and $K(X, Z)$ (resp. $W(X, Z)$ ) the subspace of compact (resp. weakly compact) operators. It is shown that (a) if $X$ contains an isomorph of $c_{0}$, then $K\left(X, l^{\infty}\right)$ is not complemented in $B\left(X, l^{\infty}\right)$, (b) if $S$ is a compact Hausdorff space which is not scattered, then $K(C(S), Z)$ is not complemented in $W(C(S), Z)$ for $Z=c_{0}$ or $l^{\infty}$. In particular, $K\left(l^{\infty}, c_{0}\right)$ is not complemented in $B\left(l^{\infty}, c_{0}\right)$, which gives a negative answer to a question proposed by Arterburn and Whitley.
\end{abstract}

A subspace $Y$ of a Banach space $X$ is complemented if there is a projection $P: X \rightarrow X$ with range $Y$, i.e., a bounded linear operator of $X$ such that $P^{2}=P$ and $P(X)=Y$. There is a general conjecture afoot that if $K(X, Z)$ is a proper subspace of $B(X, Z)$ (resp. $W(X, Z)$ ) then it is not complemented in $B(X, Z)$ (resp. $W(X, Z)$ ). This conjecture was first studied by Thorp in [8], where he proved that $K(X, Z)$ is not complemented in $B(X, Z)$ when $X, Z$ are certain Banach spaces of sequences. Later, various types of pairs $X, Z$ for which the conjecture is known to be true were exhibited in [1] and [9]. We only recall that if weak and norm sequential convergence are not the same in the dual of a separable Banach space $X$, then $K(X, Z)$ is not complemented in $W(X, Z)$ for $Z=c_{0}$ or $l^{\infty}$.

Let $S$ be a compact Hausdorff space. $S$ is called scattered if it contains no nonempty perfect subset. From the known results, we shall first establish some basic tools to determine certain situation where $K(X, Z)$ or $W(X, Z)$ is uncomplemented, then restrict ourselves to the projections in $B(X, Z)$ when $X$ contains an $\mathscr{L}^{\infty}$-space in the sense of [4] and especially when $X=C(S)$. To avoid lengthy statements, we only discuss below the projections of $B(X, Z)$ onto $K(X, Z)$ and remark here that the statements in Proposition 1 through Theorem 6 remain true if we replace $B(\cdot, \cdot)$ by $W(\cdot, \cdot)$ everywhere; and also if, instead, we replace $K(\cdot, \cdot)$ by $W(\cdot, \cdot)$ everywhere. Our results are consistent with the conjecture. Furthermore, no counterexamples to the conjecture are known at present. In the sequel, let $X^{*}$ denote the dual space of a Banach space $X$ and let $X$ be embedded into $X^{* *}$ under the canonical isometry.

Proposition 1. Let $Z$ be a Banach space such that $Z$ is comple- 
mented in $Z^{* *}$. Suppose $K(X, Z)$ is not complemented in $B(X, Z)$, then $K\left(Z^{*}, X^{*}\right)$ is not complemented in $B\left(Z^{*}, X^{*}\right)$.

Proof. The map $T \rightarrow T^{*}$ is an isometrical isomorphism of $B(X, Z)$ into $B\left(Z^{*}, X^{*}\right)$ such that $T^{*}$ is compact if and only if $T$ is. Also $T^{* *}$ is a linear extension of $T$. Suppose now $Q$ is a projection of $Z^{* *}$ onto $Z$ and $R$ is a projection of $B\left(Z^{*}, X^{*}\right)$ onto $K\left(Z^{*}, X^{*}\right)$; define $P: B(X, Z) \rightarrow B(X, Z)$ by

$$
(P T)(x)=Q\left(\left(R T^{*}\right)^{*}(x)\right) .
$$

$P$ is then a projection of $B(X, Z)$ onto $K(X, Z)$, a contradiction.

As an application, since $K\left(l^{1}, l^{1}\right)$ is not complemented in $B\left(l^{1}, l^{1}\right)$ [8], it follows that $K\left(l^{\infty}, l^{\infty}\right)$ is not complemented in $B\left(l^{\infty}, l^{\infty}\right)$, a simple result which is not contained in previous work.

Proposition 2. There exists an isometrical isomorphism of $B\left(X, Z^{*}\right)$ onto $B\left(Z, X^{*}\right)$ such that $K\left(X, Z^{*}\right)$ corresponds to $K\left(Z, X^{*}\right)$. Thus if $K\left(X, Z^{*}\right)$ is not complemented in $B\left(X, Z^{*}\right)$, neither is $K\left(Z, X^{*}\right)$ in $B\left(Z, X^{*}\right)$.

Proof. Consider $T \in B\left(X, Z^{*}\right)$. Since $Z$ is weak* dense in $Z^{* *}$, the map $\tau:\left.T \rightarrow T^{*}\right|_{z}$, the restriction of $T^{*}$ to $Z$, is an isometrical isomorphism. $\tau$ is also surjective, for given any $U \in B\left(Z, X^{*}\right)$, we have $\tau\left(\left.U^{*}\right|_{X}\right)=U$. The correspondence of the subspaces of compact operators is trivial.

REMARK. In particular, $K\left(c_{0}, l^{\infty}\right)$ is thus uncomplemented in $B\left(c_{0}, l^{\infty}\right)$ because $K\left(l^{1}, l^{1}\right)$ is uncomplemented in $B\left(l^{1}, l^{1}\right)$. This proof avoids direct expressions for the norms of operators in terms of matrix coefficients as in the original proof of [8].

Let $Y$ be a subspace of $X$. A bounded linear operator $E: B(Y, Z) \rightarrow$ $B(X, Z)$ is called a simultaneous extension if $R_{Y} E(T)=T$ for every $T \in B(Y, Z)$, where $R_{Y}$ denotes the restriction to $Y$. Suppose in addition that $E(K(Y, Z)) \subset K(X, Z)$ and that $P$ is a projection of $B(X, Z)$ onto $K(X, Z)$; then $R_{Y} P E$ is a projection of $B(Y, Z)$ onto $K(Y, Z)$. Hence we have:

Lemma 3. Suppose $K(Y, Z)$ is not complemented in $B(Y, Z)$ and that there exists a simultaneous extension $E: B(Y, Z) \rightarrow B(X, Z)$ such that $E(K(Y, Z)) \subset K(X, Z)$; then $K(X, Z)$ is not complemented in $B(X, Z)$.

Lemma 4. If $Y$ is complemented in $X$, then there exists a simultaneous extension $E$ such that $E(K(Y, Z)) \subset K(X, Z)$. 
LEMmA 5. If $Z$ is complemented in $Z^{* *}$ and $Y \subset Y_{1} \subset Y^{* *}$, then there exists a simultaneous extension $E$ from $B(Y, Z)$ to $B\left(Y_{1}, Z\right)$ with $E(K(Y, Z)) \subset K\left(Y_{1}, Z\right)$.

Proof. The map $T \rightarrow T^{* *}$ is an isometrical isomorphism from $B(Y, Z)$ into $B\left(Y^{* *}, Z^{* *}\right)$ such that $T^{* *}$ is an extension of $T$ and $T^{* *}$ is compact if and only if $T$ is. Let $P$ be a projection of $Z^{* *}$ onto $Z$. Define $E: B(Y, Z) \rightarrow B\left(Y_{1}, Z\right)$ by $(E T)(y)=P\left(T^{* *}(y)\right), y \in Y_{1}$; then $E$ is the desired simultaneous extension.

THEOREM 6. If $Z$ is complemented in $Z^{* *}$ and $Y$ is an $\mathscr{L}^{\infty}$ space such that $K(Y, Z)$ is not complemented in $B(Y, Z)$ then $K(X, Z)$ is not complemented in $B(X, Z)$ for any $X$ containing a subspace isomorphic to $Y$.

Proof. We can assume without loss of generality that $Y \subset X$, because if $Y$ is isomorphic to $\widetilde{Y}$ then $K(Y, Z)$ is complemented in $B(Y, Z)$ if and only if $K(\widetilde{Y}, Z)$ is complemented in $B(\widetilde{Y}, Z)$. Then $Y^{* *}$ can be regarded as a subspace of $X^{* *}$. Since $Y^{* *}$ is an injective space [4, p. 291], there exists a projection $Q$ from $X^{* *}$ onto $Y^{* *}$. Let $P$ be the projection from $Z^{* *}$ onto $Z$. On account of Lemma 4 and Lemma 5 , we define $E: B(Y, Z) \rightarrow B(X, Z)$ by $(E T)(x)=$ $P\left(T^{* *}(Q(x)), x \in X\right.$. Then $E$ is a simultaneous extension such that $E(K(Y, Z)) \subset K(X, Z)$, which in turn proves that $K(X, Z)$ is not complemented in $B(X, Z)$.

REMARKs. (a) $Z$ is complemented in $Z^{* *}$ if and only if $Z$ is isomorphic to a complemented subspace of a dual space. (b) A bounded linear operator $T \in B(Y, Z)$ is weakly compact if and only if $T^{* *}$ maps $Y^{* *}$ into $Z$, i.e., $T \in W(Y, Z) \Leftrightarrow T^{* *} \in W\left(Y^{* *}, Z\right)$. Hence if $B(Y, Z)=W(Y, Z)$, or if we are merely looking for a projection of $W(X, Z)$ onto $K(X, Z)$, the assumption that $Z$ is complemented in $Z^{* *}$ is redundant.

Observe that $c_{0}$ is an $\mathscr{L}^{\infty}$-space [4, p. 283]. Therefore, since there exists no projection of $B\left(c_{0}, l^{\infty}\right)$ onto $K\left(c_{0}, l^{\infty}\right)$ and since every infinitedimensional Banach space whose dual is an $L^{1}$ space contains a subspace isomorphic to $c_{0}[10]$, we have

Corollary 7. If $X$ contains a subspace isomorphic to $c_{0}$, which is in particular the case when $X$ is isomorphic to a $C(S)$ space or $X$ is an infinite-dimensional Banach space whose dual is an $L^{1}$ space, then $K\left(X, l^{\infty}\right)$ is not complemented in $B\left(X, l^{\infty}\right)$.

REMARK. An infinite-dimensional Banach space whose dual is an 
$L^{1}$ space need not be isomorphic to a $C(S)$ space. As an example, given by Benyamini and Lindenstrauss, there exists a predual of $l^{1}$ which is not isomorphic to any $C(S)$ space [2].

In connection with the linear extension of operators, we have the following corollary, which will serve as a lemma for the next theorem.

Corollary 8. If $Y$ is an $\mathscr{L}^{\infty}$-space and $X$ contains $Y$, then there exists a simultaneous extension $E$ from $W(Y, Z)$ to $W(X, Z)$ such that $E(K(Y, Z)) \subset K(X, Z)$. If in addition $Z$ is complemented in $Z^{* *}$, then there exists a simultaneous extension from $B(Y, Z)$ to $B(X, Z)$ with $K(Y, Z)$ and $W(Y, Z)$ corresponding to subspaces of $K(X, Z)$ and $W(X, Z)$ respectively.

THEOREM 9. Let $S$ be a compact Hausdorff space which is not scattered, then $K(C(S), Z)$ is not complemented in $W(C(S), Z)$ for $Z=c_{0}$ or $Z=l^{\infty}$.

Proof. Consider the space $C([0,1])$. Since weak and norm sequential convergence are not the same in $C([0,1])^{*}$, it is known by the aforementioned result in [1] that $K(C([0,1]), Z)$ is not complemented in $W(C([0,1]), Z)$ when $Z$ is $c_{0}$ or $l^{\infty}$. Now if $S$ is not scattered, the interval $[0,1]$ is a continuous image of $S$ [7], hence $C(S)$ contains an isometric copy of $C([0,1])$. Therefore by Corollary 8 , there exists a simultaneous extension from $W(C([0,1]), Z)$ to $W(C(S), Z)$ such that $K(C([0,1]), Z)$ corresponds to a subspace of $K(C(S), Z)$. It follows then from Lemma 3 that $K(C(S), Z)$ is not complemented in $W(C(S), Z)$.

In answer to a question raised by Arterburn and Whitley in [1], where they asked whether $K\left(l^{\infty}, c_{0}\right)$ is complemented in $B\left(l^{\infty}, c_{0}\right)$, we have the following corollary, though an independent proof has been given in [9].

Corollary 10. $K\left(l^{\infty}, c_{0}\right)$ is not complemented in $B\left(l^{\infty}, c_{0}\right)$.

Proof. Since $l^{\infty}$ can be identified with $C(\beta N)$ and $\beta N$ is not scattered, the desired result follows immediately from Theorem 9.

Finally, to complete the examples studied by Tong and Wilken in [9], we consider the space of bounded linear operators $B(C(S), Z), Z=c_{0}$ or $Z=l^{p}, 1 \leqq p \leqq \infty$. Suppose $S$ is scattered; then, since $C(S)^{*}$ is isometric to $l^{1}(S), K(C(S), Z)=W(C(S), Z)$. (Recall that weak convergent sequences in $l^{1}(S)$ are norm convergent $[3$, p. 33] and a bounded linear operator $T$ is compact if and only if $T^{*}$ has 
the same property.) But it is well known that $W(C(S), Z)=B(C(S), Z)$ for an arbitrary Banach space $Z$ containing no subspace isomorphic to $c_{0}$ [6], hence $K(C(S), Z)=B(C(S), Z)$ for $Z=l^{p}, 1 \leqq p<\infty$. When $Z=c_{0}$ or $Z=l^{\infty}$, then since $C(S)$ contains a complemented copy of $c_{0}, K(C(S), Z)$ is not complemented in $B(C(S), Z)$. If $S$ is not scattered and $Z=c_{0}$ or $Z=l^{\infty}$, it is clear that $K(C(S), Z)$ is not complemented in $W(C(S), Z$ ) (and hence not complemented in $B(C(S), Z)$ ) by Theorem 9 . For $Z=l^{p}, 2 \leqq p \leqq \infty, K(C(S), Z)$ is not complemented in $B(C(S), Z)$ by the main theorem in [9] and the fact that there exists a noncompact operator from $C(S)$ into $Z$ as indicated there. When $Z=l^{p}, 1 \leqq p<2$, the question of the existence of a noncompact operator was left open in the same reference; the answer is no, as follows from a factorization theorem:

THEOREM 11. Every bounded linear operator from an $\mathscr{L}^{\infty}$-space into $l^{p}, 1 \leqq p<2$ is compact.

Proof. By Theorem 5.2 in [4], every bounded linear operator from an $\mathscr{L}^{\infty}$-space into $l^{p}, 1 \leqq p<2$ can be factorized through a Hilbert space. Indeed, since $l^{p}$ is separable, the Hilbert space $H$ can further be chosen to be $l^{2}$. For if $T: H \rightarrow l^{p}$, then $T$ can be factorized as $H \stackrel{\Phi}{\rightarrow} H / N \stackrel{\hat{T}}{\rightarrow} l^{p}$, where $N$ is the null space of $T, \Phi$ is the quotient map and $\widehat{T}$ is the induced injective map. Now since $\hat{T}^{*}: l^{q} \rightarrow H / N$ has a weak* dense image (hence weakly dense, since $H / N$ is reflexive), $H / N$ must be separable, which implies that $H / N$ is isomorphic to $l^{2}$. The desired result then follows from the fact that every bounded linear operator from $l^{2}$ into $l^{p}, 1 \leqq p<2$ is compact.

\section{REFERENCES}

1. D. Arterburn and R. Whitley, Projections in the space of bounded linear operators, Pacific J. Math., 15 (1965), 739-746.

2. Y. Benyamini and J. Lindenstrauss, A predual of $l^{1}$ which is not isomorphic to a $C(K)$ space, Isreal J. Math., 13 (1972), 246-254.

3. M. M. Day, Normed Linear Spaces, Springer-Verlag, 1958.

4. J. Lindenstrauss and A. Pelczyński, Absolutely summing operators in $\mathscr{L}_{p}$ spaces and their applications, Studies Math., 29 (1968), 275-326.

5. J. Lindenstrauss and H. P. Rosenthal, Automorphisms in $c_{0}, l^{1}$, and $m$, Israel J. Math., 7 (1969), 227-239.

6. A. Pelczyński, Projections in certain Banach spaces, Studia Math., 19 (1960), 209228.

7. A. Pelczyński and Z. Semadeni, Spaces of continuous functions (III), Studia Math., 18 (1959), 211-222.

8. E. Thorp, Projections onto the subspaces of compact operators, Pacific J. Math., 10 (1960), 693-696.

9. A. E. Tong and D. R. Wilken, The uncomplemented subspaces $K(E, F)$, Studia 
Math., 37 (1971), 227-236.

10. M. Zippin, On some subspaces of Banach spaces whose duals are $L^{1}$ spaces, Proc. Amer. Math. Soc., 23 (1969), 378-385.

Received August 15, 1973 and in revised form January 21, 1974. The author is grateful to Professor J. J. Schäffer for his help during the preparation of this paper and to the referee for a suggestion simplifying the proof of Theorem 6 .

\section{CARNEGIE-MeLLON UNIVERSITY}




\section{PACIFIC JOURNAL OF MATHEMATICS}

EDITORS

RICHARD ARens (Managing Editor)

University of California

Los Angeles, California 90024

\section{R. A. Beaumont}

University of Washington

Seattle. Washington 98105

\section{J. DugundjI}

Department of Mathematics University of Southern California Los Angeles, California 90007

D. Gilbarg and J. Milgram

Stanford University

Stanford. California 94305

\section{ASSOCIATE EDITORS}
E. F. BECKENBACH
B. H. NEUMANN
F. WOLF
K. Yoshida

\section{SUPPORTING INSTITUTIONS}

\author{
UNIVERSITY OF BRITISH COLUMBIA \\ CALIFORNIA INSTITUTE OF TECHNOLOGY \\ UNIVERSITY OF CALIFORNIA \\ MONTANA STATE UNIVERSITY \\ UNIVERSITY OF NEVADA \\ NEW MEXICO STATE UNIVERSITY \\ OREGON STATE UNIVERSITY \\ UNIVERSITY OF OREGON \\ OSAKA UNIVERSITY
}

\author{
UNIVERSITY OF SOUTHERN CALIFORNIA \\ STANFORD UNIVERSITY \\ UNIVERSITY OF TOKYO \\ UNIVERSITY OF UTAH \\ WASHINGTON STATE UNIVERSITY \\ UNIVERSITY OF WASHINGTON

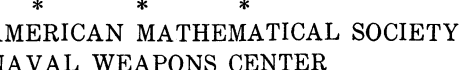

The Supporting Institutions listed above contribute to the cost of publication of this Journal, but they are not owners or publishers and have no responsibility for its content or policies.

Mathematical papers intended for publication in the Pacific Journal of Mathematics should be in typed form or offset-reproduced, (not dittoed), double spaced with large margins. Underline Greek letters in red, German in green, and script in blue. The first paragraph or two must be capable of being used separately as a synopsis of the entire paper. Items of the bibliography should not be cited there unless absolutely necessary, in which case they must be identified by author and Journal, rather than by item number. Manuscripts, in duplicate if possible, may be sent to any one of the four editors. Please classify according to the scheme of Math. Rev. Index to Vol. 39. All other communications to the editors should be addressed to the managing editor, or Elaine Barth, University of California, Los Angeles, California, 90024.

100 reprints are provided free for each article, only if page charges have been substantially paid Additional copies may be obtained at cost in multiples of 50 .

The Pacific of Journal Mathematics is issued monthly as of January 1966. Regular subscription rate: $\$ 72.00$ a year (6 Vols., 12 issues). Special rate: $\$ 36.00$ a year to individual members of supporting institutions.

Subscriptions, orders for back numbers, and changes of address should be sent to Pacific Journal of Mathematics, 103 Highland Boulevard, Berkeley, California, 94708.

\section{PUBLISHED BY PACIFIC JOURNAL OF MATHEMATICS, A NON-PROFIT CORPORATION}

Printed at Kokusai Bunken Insatsusha (International Academic Printing Co., Ltd.), 270, 3-chome Totsuka-cho. Shinjuku-ku, Tokyo 160. Japan.

Copyright (C) 1973 by Pacific Journal of Mathematics Manufactured and first issued in Japan 


\section{Pacific Journal of Mathematics}

\section{Vol. 52, No. $2 \quad$ February, 1974}

Harm Bart, Spectral properties of locally holomorphic vector-valued functions .....

J. Adrian (John) Bondy and Robert Louis Hemminger, Reconstructing infinite

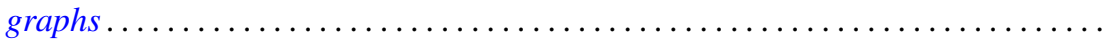

Bryan Edmund Cain and Richard J. Tondra, Biholomorphic approximation of planar

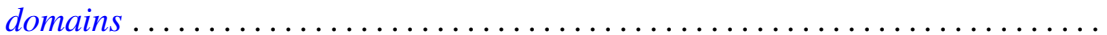

Richard Carey and Joel David Pincus, Eigenvalues of seminormal operators,

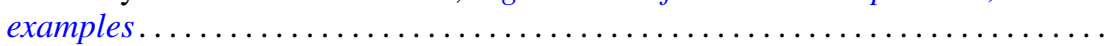

Tyrone Duncan, Absolute continuity for abstract Wiener spaces . . . . . . . . . . . . Joe Wayne Fisher and Louis Halle Rowen, An embedding of semiprime

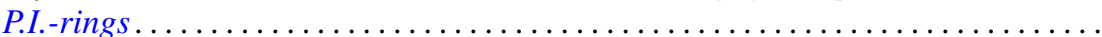

Andrew S. Geue, Precompact and collectively semi-precompact sets of semi-precompact continuous linear operators. . . . . . . . . . . . . . . .

Charles Lemuel Hagopian, Locally homeomorphic $\lambda$ connected plane continua ..... . Darald Joe Hartfiel, A study of convex sets of stochastic matrices induced by

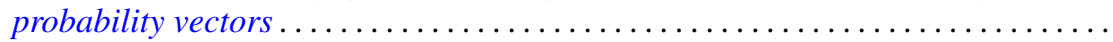

Yasunori Ishibashi, Some remarks on high order derivations $\ldots \ldots \ldots \ldots \ldots \ldots \ldots$ Donald Gordon James, Orthogonal groups of dyadic unimodular quadratic forms.

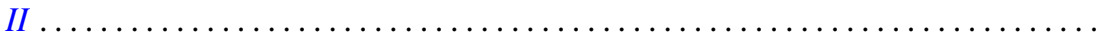

Geoffrey Thomas Jones, Projective pseudo-complemented semilattices . . . . . . . . . Darrell Conley Kent, Kelly Denis McKennon, G. Richardson and M. Schroder,

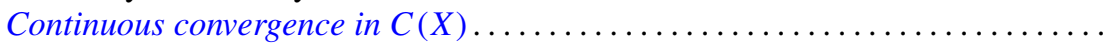

J. J. Koliha, Some convergence theorems in Banach algebras ...

Tsang Hai Kuo, Projections in the spaces of bounded linear oper

George Berry Leeman, Jr., A local estimate for typically real functions . .

475

Andrew Guy Markoe, A characterization of normal analytic spaces by the

homological codimension of the structure sheaf .........

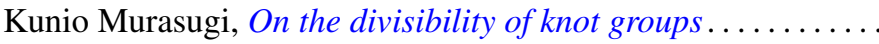

John Phillips, Perturbations of type I von Neumann algebras.

Billy E. Rhoades, Commutants of some quasi-Hausdorff matrices . .

David W. Roeder, Category theory applied to Pontryagin duality

Maxwell Alexander Rosenlicht, The nonminimality of the differential closure .

Peter Michael Rosenthal, On an inversion theorem for the general Mehler-Fock transform pair.

Alan Saleski, Stopping times for Bernoulli automorphisms

John Herman Scheuneman, Fundamental groups of compact complete locally affine complex surfaces. II. ........................

Vashishtha Narayan Singh, Reproducing kernels and operators with a cyclic vector. I. .

Peggy Strait, On the maximum and minimum of partial sums of random variables.

J. L. Brenner, Maximal ideals in the near ring of polynomials modulo 2 .

Ernst Gabor Straus, Remark on the preceding paper: "Ideals in near rings of polynomials over a field" ..........................

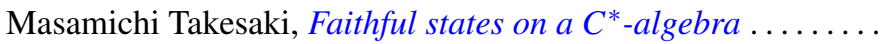

R. Michael Tanner, Some content maximizing properties of the regular simplex.

Andrew Bao-hwa Wang, An analogue of the Paley-Wiener theorem for certain

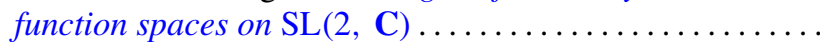

